\title{
Rapid genomic and transcriptomic alterations induced by wide hybridization: Chrysanthemum nankingense $\times$ Tanacetum vulgare and C. crassum $\times$ Crossostephium chinense (Asteraceae)
}

Haibin Wang ${ }^{1,2}$, Jiafu Jiang ${ }^{1 *}$, Sumei Chen ${ }^{1}$, Weimin Fang ${ }^{1}$, Zhiyong Guan ${ }^{1}$, Yuan Liao ${ }^{1}$ and Fadi Chen ${ }^{1,2^{*}}$

\begin{abstract}
Background: Hybridization is a major driver of evolution in plants. In a number of plant species, the process of hybridization has been revealed to be accompanied by wide-ranging genetic and epigenetic alterations, some of which have consequences on gene transcripts. The Asteraceae family includes a number of polyploid species, and wide crossing is seen as a viable means of genetically improving ornamental species such as Chrysanthemum spp. However, the consequences of hybridization in this taxon have yet to be characterized.

Results: Amplified fragment length polymorphism (AFLP), methylation sensitive amplification polymorphism (MSAP) and CDNA-AFLP profiling of the two intergeneric hybrids $C$. nankingense $\times$ Tanacetum vulgare and $C$. crassum $\times$ Crossostephium chinense were employed to characterize, respectively, the genomic, epigenomic and transcriptomic changes induced by the hybridization event. The hybrids' AFLP profiles included both the loss of specific parental fragments and the gain of fragments not present in either parent's profile. About $10 \%$ of the paternal fragments were not inherited by the hybrid, while the corresponding rate for the maternal parent fragments was around $4-5 \%$. The novel fragments detected may have arisen either due to heterozygosity in one or other parent, or as a result of a deletion event following the hybridization. Around one half of the CDNA-AFLP fragments were common to both parents, about 30\% were specific to the female parent, and somewhat under $20 \%$ specific to the male parent; the remainder (2.9-4.7\%) of the hybrids' fragments were not present in either parent's profile. The MSAP fingerprinting demonstrated that the hybridization event also reduced the amount of global cytosine methylation, since $>50 \%$ of the parental fragments were methylated, while the corresponding frequencies for the two hybrids were $48.5 \%$ and $50.4 \%$.
\end{abstract}

Conclusions: Combining two different Asteraceae genomes via hybridization clearly induced a range of genomic and epigenomic alterations, some of which had an effect on the transcriptome. The rapid genomic and transcriptomic alterations induced by hybridization may accelerate the evolutionary process among progenies.

Keywords: Genome evolution, Gene transcripts, Cytosine methylation, Wide hybridization, Asteraceae

\footnotetext{
* Correspondence: jiangjiafu@njau.edu.cn; chenfd@njau.edu.cn

${ }^{1}$ College of Horticulture, Nanjing Agricultural University, No. 1 Weigang,

Nanjing 210095, Jiangsu Province, China

${ }^{2}$ Jiangsu Province Engineering Lab for Modern Facility Agriculture

Technology \& Equipment, No. 1 Weigang, Nanjing 210095, Jiangsu Province, China
} 


\section{Background}

Hybridization has contributed substantially to the evolution of higher plants, both in the context of extending genetic diversity and in enhancing adaptive speciation [1-3]. At least $70 \%$ of angiosperm species are polyploid, of which the majorities are allo- rather than autopolyploid [4]. Detailed analysis of the genome of many species held to be diploid has revealed that many of these are in fact cryptic polyploids [5], at various stages of decay back to the diploid state [6-10].

Although been debated for more than a century, hybridization is considered to be a potent evolutionary force of genetic variation and functional novelty and occurs frequently in flower plant [11,12]. The allopolyploid state often offers several adaptive advantages over the diploid state. Adaptive advantages include the acquisition of novel gene combinations which can in some cases promote heterosis [13], the duplication of gene functions which can provide an element of buffering, and the potential to evolve novel functionality which were predicted by McClintock as "genomic shock" [1,14]. Hybridization appears to often be accompanied by changes to both genomic sequences, to the epigenome and to the pattern of gene transcripts [15-22]. Some of the latter have been revealed to have been induced by epigenetic, rather than by genetic changes, in particular as a consequence of altered profiles of cytosine methylation which is one of the major and immediate epigenetic responses of the plant genome to hybridization and also play an important role in the regulation of gene transcripts [23-25].

In plant breeding and domestication process, hybridization is a powerful method to import excellent genes and exquisite traits into hybrids (either caused by additive or non-additive effects), which results in the phenotypic superiority of a hybrid over its parents with respect to traits such as greater biomass, speed of development and yield [26,27]. Compared with interspecific hybridization, intergeneric hybridization is more difficult to succeed, and the overall results have not resolved the controversy as to whether intergeneric hybrids have undergone rapid and directed changes in genome change in their evolutionary history [28-30]. Furthermore, the proportion and categories of DNA or CDNA sequences affected by the species differ in various families. Hence, to promote a better understanding of the success of plants, further independent wide hybridization events need to be analyzed in future studies.

Asteraceae is a large group of angiosperms distributed all over the world includes ploidy states ranging from diploid (eg. C. nankingense) to decaploid (eg. C. crassum) which is generally considered to be an advanced subjects and at the forefront of the evolution [31-33]. Despite numerous studies showed valuable information about rapid genetic and epigenetic changes in many other plants, as a large species group, little is known about these changes in Chrysanthemum even in Asteraceae [34,35]. In the early studies, intergeneric hybrids have been successfully created using a wide range of parental materials and some of these hybrids have proven to make highly vigorous plants [36,37]. Here, DNA-AFLP and MSAP fingerprinting were applied to characterize induced changes in the genome and epigenome, and cDNA-AFLP were used to detect changes to the transcriptome in newly synthesized $C$. nankingense $\times$ Tanacetum vulgare and C. crassum $\times$ Crossostephium chinense hybrids.

\section{Methods}

\section{Plant materials}

The relevant accessions of $C$. nankingense, T. vulgare and their $\mathrm{F}_{1}$ hybrid (Figure 1A), and of C. crassum, Cr. chinense and their $\mathrm{F}_{1}$ hybrid (Figure $1 \mathrm{~B}$ ) were obtained from the Chrysanthemum Germplasm Resource Preserving Centre, Nanjing Agricultural University, China $\left(32^{\circ} 05^{\prime} \mathrm{N}, 118^{\circ} 8^{\prime} \mathrm{E}, 58 \mathrm{~m}\right.$ altitude). All plants were propagated by cuttings; the medium contained a $2: 2: 1(\mathrm{v} / \mathrm{v})$ mixture of perlite, vermiculite and leaf mould, respectively. Rooted seedlings were grown in a greenhouse under conditions held at $22^{\circ} \mathrm{C}$ during the day and at a minimum of $15^{\circ} \mathrm{C}$ during the night. The relative humidity varied from 70 to $75 \%(\mathrm{~m} / \mathrm{m})$, and no artificial light was given. The experiment included three biological replications.

Intergeneric cross was performed at 9:00-10:00 am on a sunny day, the bisexual tubular florets of female were removed and the inflorescences were enclosed within a paper bag. After two to three days, fresh pollen of the male donor was brushed onto the pistil when the stigmas first became visible and re-bagged. The $F_{1}$ hybrids were obtained via ovule rescue at 10-15 days after pollination [36,37].

\section{Nucleic acid extraction and cDNA synthesis}

Genomic DNA was extracted from fully expanded third and the fourth leaves collected from three biological replication per entry using a CTAB-based method [38], followed by a pectinase and cellulase treatment and the application of a Nuclei Isolation Kit (Solarbio, China). Total RNA was isolated from a similar set of leaves using the TRIzol reagent (Takara, Japan), based on the manufacturer's protocol. Prior to its reverse transcription, the total RNA preparation was digested for $30 \mathrm{~min}$ at $37^{\circ} \mathrm{C}$ with RNase-free DNase I (Takara, EC 3.1.4.5) to remove any contaminating genomic DNA. The first cDNA strand was synthesized from a 300 ng RNA based on random priming and SuperScript III Reverse Transcriptase (Takara, EC 2.7.7.49). The second strand was then synthesized by the addition of $10 \mathrm{U}$ DNA polymerase I (Takara, EC 2.7.7.7) and 5 U RNase H (Takara, EC 3.1.26.4) [39], and purified by extraction in phenol: 

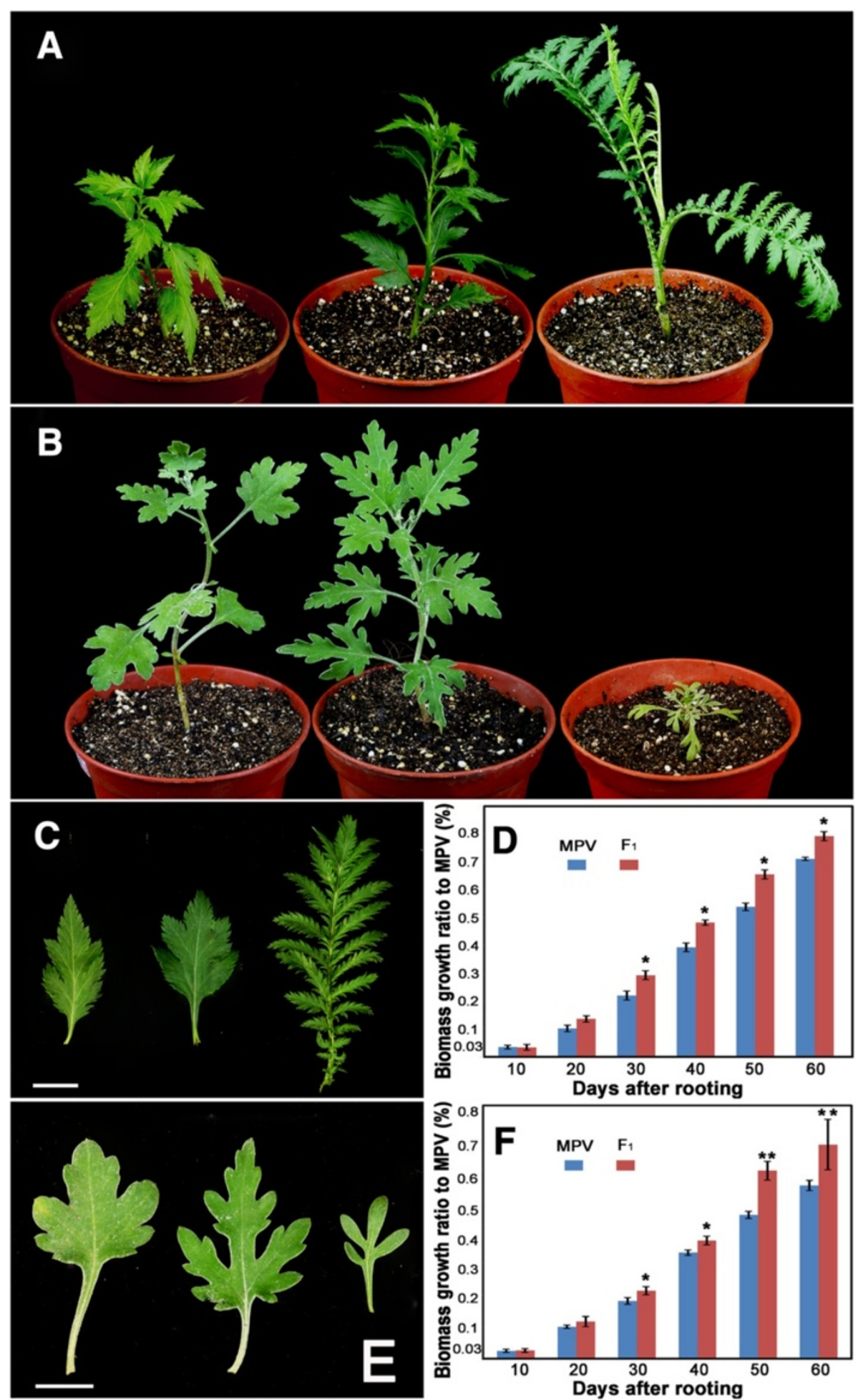

Figure 1 The phenotype of materials. The phenotype of (A) C. nankingense (left), T. vulgare (right) and their hybrid (center), (B) C. crassum (left), Cr. chinense (right) and their hybrid (center). (C) Leaf morphology of C. nankingense (left), T. vulgare (right) and their hybrid (center). Bars: $1 \mathrm{~cm}$. (E) Leaf morphology of C. crassum (left), Cr. chinense (right) and their hybrid (center). Bars: $1 \mathrm{~cm}$. Values shown are the mean and SE of biomass growth ratio to MPV of (D) the $C$. nankingense $\times T$. vulgare hybrid and $(\mathbf{F})$ the $C$. crassum $\times C$. chinense hybrid, measured ten, 20, 30, 40, 50 and 60 days after rooting. $n$ : number of plants. ${ }^{*} \mathrm{P}<0.05$; ${ }^{* *} \mathrm{P}<0.01$. 
Table 1 Sequences of adaptors and primers used for pre-amplification and selective amplification in AFLP and MSAP analysis

\begin{tabular}{|c|c|}
\hline Adaptors/primers & Sequence $\left(5^{\prime}-3^{\prime}\right)$ \\
\hline Msel adaptor-1 & GACGATGAGTCCTGAG \\
\hline Msel adaptor-2 & TACTCAGGACTCAT \\
\hline EcoRI adaptor-1 & CTCGTAGACTGCGTACC \\
\hline EcoRI adaptor-2 & AATTGGTACGCAGTCTAC \\
\hline Hpall/Mspl adaptor-1 & GATCATGAGTCCTGCT \\
\hline Hpall/Mspl adaptor-2 & CGAGCAGGACTCATGA \\
\hline EcoRI pre-selective primer & GACTGCGTACCAATTCA \\
\hline Msel pre-selective primer & GATGAGTCCTGAGTAAC \\
\hline Hpall/Mspl pre-selective primer & ATCATGAGTCCTGCTCGG \\
\hline EcoRI selective primer-2 & GACTGCGTACCAATTCAAG \\
\hline EcoRI selective primer-3 & GACTGCGTACCAATTCACA \\
\hline EcoRI selective primer-4 & GACTGCGTACCAATTCACT \\
\hline EcoRI selective primer-5 & GACTGCGTACCAATTCACC \\
\hline EcoRI selective primer- 6 & GACTGCGTACCAATTCACG \\
\hline EcoRI selective primer-7 & GACTGCGTACCAATTCAGC \\
\hline EcoRI selective primer-8 & GACTGCGTACCAATTCAGG \\
\hline Msel selective primer-2 & GATGAGTCCTGAGTAACAC \\
\hline Msel selective primer-3 & GATGAGTCCTGAGTAACAG \\
\hline Msel selective primer-5 & GATGAGTCCTGAGTAACTA \\
\hline Msel selective primer-6 & GATGAGTCCTGAGTAACTC \\
\hline Msel selective primer-7 & GATGAGTCCTGAGTAACTG \\
\hline Msel selective primer-8 & GATGAGTCCTGAGTAACTT \\
\hline Hpall/Mspl selective primer-1 & ATCATGAGTCCTGCTCGGTAA \\
\hline Hpall/Mspl selective primer-2 & ATCATGAGTCCTGCTCGGTCC \\
\hline Hpall/Mspl selective primer-3 & ATCATGAGTCCTGCTCGGTTC \\
\hline Hpall/Mspl selective primer-6 & ATCATGAGTCCTGCTCGGTAG \\
\hline Hpall/Mspl selective primer-7 & ATCATGAGTCCTGCTCGGTTG \\
\hline Hpall/Mspl selective primer-8 & ATCATGAGTCCTGCTCGGTCA \\
\hline
\end{tabular}

chloroform: isoamyl alcohol (25:24:1, v/v) followed by ethanol precipitation. The purified products were each dissolved in $50 \mu \mathrm{L} d \mathrm{ddH}_{2} \mathrm{O}$.

\section{DNA/cDNA fingerprinting}

The AFLP protocol used to profile the genomic DNA and CDNA was a minor modification of the one described by Vos et al. [40]. The first PCR amplification performed with the AFLP ligation and pre-selective amplification module from PE Biosystems. After diluted in a ratio of $1: 30$ with $d_{d d} \mathrm{O}$, the PCR product was used as templates for the selective amplification with three selective bases. The selective amplification reactions were based on the nine primer combinations EcoRI_2/MseI_5 (abbreviated as 'E2 + M5'), E2 + M6, $\mathrm{E} 3+\mathrm{M} 2, \mathrm{E} 4+\mathrm{M} 3, \mathrm{E} 4+\mathrm{M} 8, \mathrm{E} 6+\mathrm{M} 7, \mathrm{E} 7+\mathrm{M} 3, \mathrm{E} 8+\mathrm{M} 3$ and E8 + M7; each primer included three selective bases (sequences of adaptors and primers given in Table 1), and the EcoRI primers were labeled with 5-FAM. Each PCR was replicated once, and two aliquots of each reaction were electrophoresed independently through denaturing polyacrylamide gels $(5 \%(\mathrm{v} / \mathrm{v})$ Long Ranger; $36 \mathrm{~cm}$ in length) for $2 \mathrm{~h}$ at $65 \mathrm{~W}$. Only reproducible fragments in the size range $100-500$ bp of two replications were recorded as present (1) or absent (0).

Differential methylation of the genomic DNA was analyzed by the AFLP-based MSAP technique, based on the isoschizomeric pair HpaII (New England Biolabs, China, EC 3.1.23.24) and MspI (NEB, EC 3.1.23.24), in combination with EcoRI (NEB, EC 3.1.23.13). Methylation polymorphisms at $5^{\prime}$-CCGG-3' tetranucleotide sites generate differences between the EcoRI-HpaII (H lanes) and EcoRI-MspI (M lanes) profiles [41,42]. About 500 ng of each cDNA was digested with either $10 \mathrm{U} \mathrm{EcoRI}$ and $20 \mathrm{U}$ HpaII or $10 \mathrm{U}$ EcoRI and $10 \mathrm{U}$ Msplat $37^{\circ} \mathrm{C}$ for $12 \mathrm{~h}$. The digested fragments were ligated to 5 pmol EcoRI adaptor and 50 pmol HpaIIMspI adaptor by incubation with $4 \mathrm{U}$ T4 DNA polymerase (NEB, EC 2.7.7.7) at $16^{\circ} \mathrm{C}$ for $4 \mathrm{~h}$. Amplicons derived from a pre-selective amplification based on EcoRI pre-selective primer and HpaII/MspI preselective primer formed the template for a subsequent selective amplification.Selective amplification reaction was based on one of nine primer combinations (E2 + HM6, E4 + HM3, E4 + HM7, E4 + HM8, E6 + HM6, E6 + HM8, E7 + HM1, E8 + HM2 and E8 + HM8; adaptor and primer sequences listed in Table 1). Reaction products were electrophoresed in the same way as were the AFLP products. Electrophoresis profiles were used to derive a difference between the mid-parental value and the hybrids, according to the formula,

$$
\begin{aligned}
p & =\frac{\mathrm{y} 1+\mathrm{y} 2}{n 1+n 2} ; q=1-p ; \delta_{p 1-p 2}=\sqrt{p q\left(\frac{1}{n 1}+\frac{1}{n 2}\right)} ; \\
U & =\frac{p 1-p 2}{\delta_{p 1-p 2}}
\end{aligned}
$$

In which $n 1$ represented the total sites of the midparent values, $n 2$ the number of fragments in their hybrid, y1 the total DNA methylation sites, hemimethylation sites or fully methylation sites of the mid-parent values, y2 represents the total DNA methylation sites, hemimethylation sites, or fully methylation sites of a hybrid, $p 1$ the percentage of total methylation sites, hemimethylation sites or fully methylation sites for the mid-parent values and $p 2$ the percentage of total methylation sites, hemimethylation sites or fully methylation sites for a hybrid. 


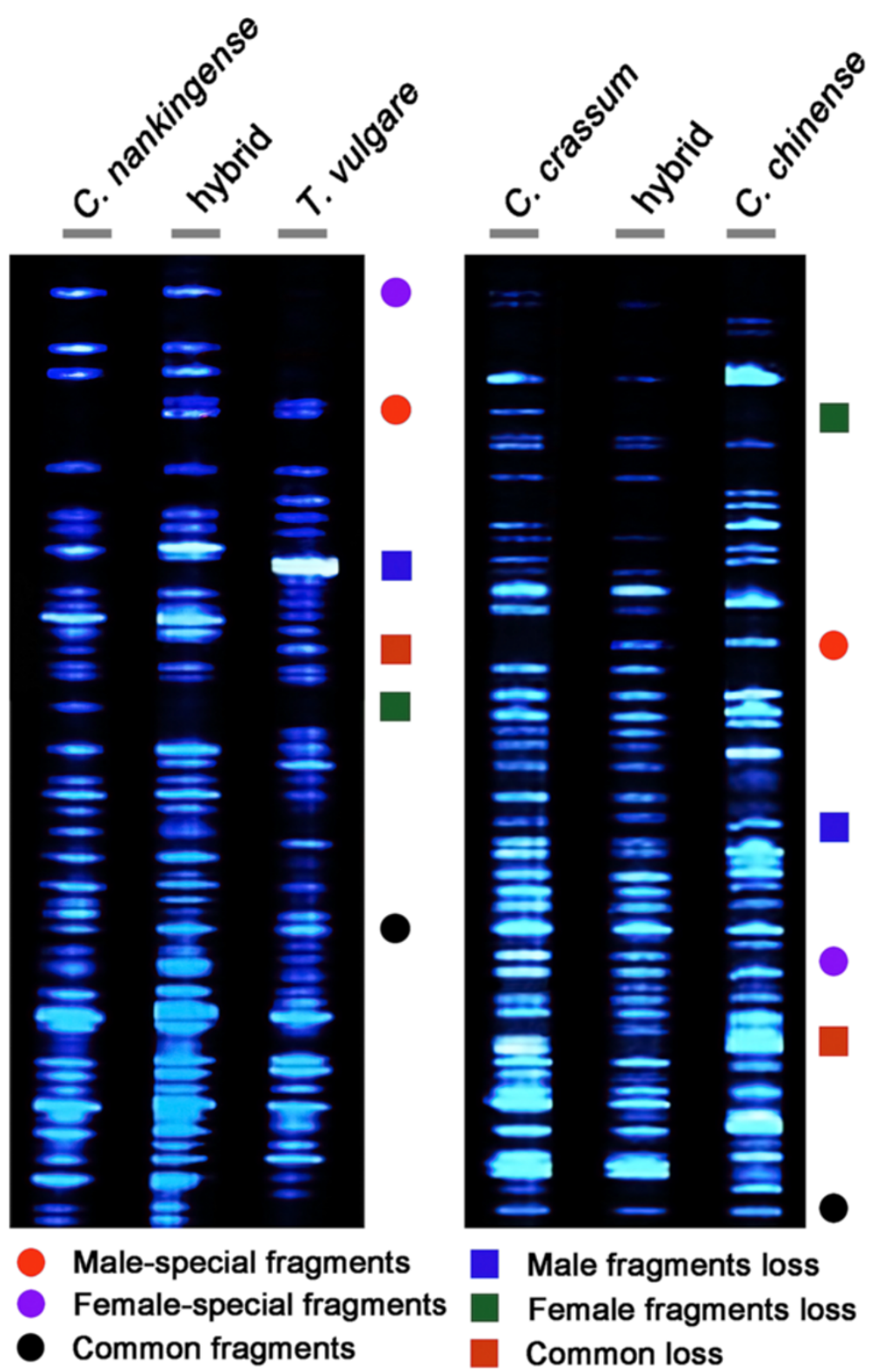

Figure 2 Typical AFLP profiles of the hybrids and their parents.

Table 2 Fragments type in two independent DNA-AFLP analyses

\begin{tabular}{|c|c|c|c|c|}
\hline \multirow[t]{2}{*}{ Fragments type } & \multicolumn{2}{|c|}{ C. nankingense $\times T$. vulgare } & \multicolumn{2}{|c|}{ C. crassum $\times$ Cr. chinense } \\
\hline & Number & Percentage & Number & Percentage \\
\hline Common fragments & 184 & $42.9 \%$ & 180 & $40.1 \%$ \\
\hline Female-special fragments & 146 & $34.0 \%$ & 162 & $36.1 \%$ \\
\hline Male-special fragments & 95 & $22.1 \%$ & 103 & $22.9 \%$ \\
\hline Novel fragments & 4 & $0.9 \%$ & 4 & $0.9 \%$ \\
\hline Total fragments & 429 & $100 \%$ & 449 & $100 \%$ \\
\hline
\end{tabular}


Table 3 DNA-AFLP fragments loss type in $F_{1}$ hybrids and their corresponding parents

\begin{tabular}{|c|c|c|c|c|c|c|c|c|}
\hline \multirow[t]{3}{*}{ Fragments type } & \multicolumn{4}{|c|}{ C. nankingense $\times T$. vulgare } & \multicolumn{4}{|c|}{ C. crassum $\times$ Cr. chinense } \\
\hline & \multirow[t]{2}{*}{ Number } & \multicolumn{3}{|c|}{ Total number } & \multirow[t]{2}{*}{ Number } & \multicolumn{3}{|c|}{ Total number } \\
\hline & & Female & Hybrid & Male & & Female & Hybrid & Male \\
\hline Female fragments loss & 18 & 355 & - & - & 16 & 367 & - & - \\
\hline Male fragments loss & 35 & - & - & 321 & 33 & - & - & 325 \\
\hline Common loss & 7 & - & - & - & 9 & - & - & - \\
\hline Novel fragments & 4 & - & 429 & - & 4 & - & 449 & - \\
\hline
\end{tabular}

\section{Results and discussion}

Alterations in the genome sequence of the newly synthesized allopolyploids

As all hybrids were obtained from inbred parental lines and no parental fragment disappearance was not caused by chromosome elimination in the previously published studies [36,37], every independently made $F_{1}$ hybrid had the same phenotypic and band patterns, one would not expect to observe much change according to conventional theory. In fact, hybrids fragments were nearly all inherited from their maternal parent. For example, of the total of 429 AFLP fragments detected in the C. nankingense $\times$ T. vulgare hybrid, all but four (i.e., $99.1 \%$ of all AFLP fragments) were present in one or both of the parents. The same frequency applied for the C. crassum $\times$ Cr. chinense hybrid (445/449 fragments; Figure 2, Table 2). In addition, about $>40 \%$ common fragments, subjects heterozygous for genetic polymorphism compared to parents show a significant consequence of hybridization effect, herein refers to $>22 \%$ male-special fragments and $>34 \%$ female-special fragments (Figure 2 and Table 2). A relatively high frequency of maternal fragments are also identified for some RFLP analyses of Phaseolus hybrids [43,44], suggesting that differential transmission of gene loci in the present study may be not a random trait derived from hybridization.

Besides the additives from the contributing parents, the nascent $F_{1}$ hybrids often show subtle fragment variations. Two major types of genetic changes are recognized in the $F_{1}$ hybrid plant: loss of parental fragments (Figure 2 and Table 3) and gain of novel fragments (Table 3). Both hybrids failed to inherit a number of parental fragments; specifically, around $10 \%$ of the paternal fragments were not present in the hybrid profiles (35/321 and 33/325), while the equivalent rate of loss from the maternal parents was $5.1 \%(18 / 355)$ for one hybrid, and $4.4 \%(16 / 367)$ for the other. The rates are all somewhat higher than what has been reported in newly synthesized hybrids such as wheat [29]. Although, loss events may reflect some residual heterozygosity in the parents, the greatest possible or the most of loss fragment is more likely to represent spontaneous deletions occurred as a manifestation of genomic shock in the process of hybridization $[1,4,8,11,45]$. Interestingly, compared to loss events, the novel fragments were calculated as only $0.9 \%$ (Table 3 ). The non-parental AFLP fragments in the DNA-AFLP analysis might be the result of allelic variation present in one of the parental species or also a spontaneous deletion that occurred in the $\mathrm{F}_{1}$ hybrid.

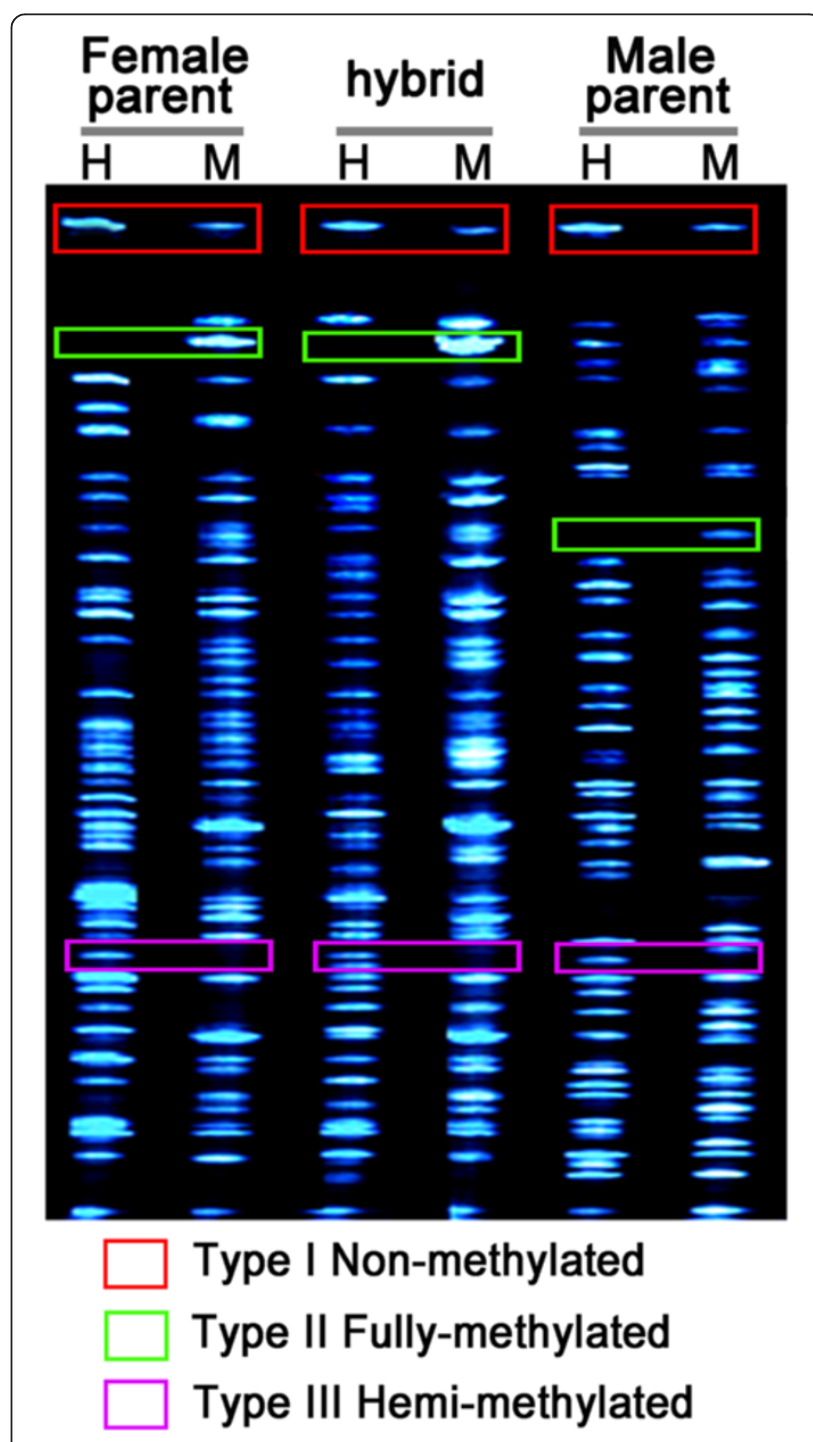

Figure 3 Typical cDNA-AFLP profiles of the hybrids and their parents. 
Table 4 Levels of cytosine methylation in $F_{1}$ hybrids and their corresponding parents

\begin{tabular}{|c|c|c|c|c|c|}
\hline \multirow[t]{2}{*}{ Plant lines } & \multirow[t]{2}{*}{ Total sites } & \multirow{2}{*}{$\begin{array}{c}\text { Non-methylated } \\
\text { Type I }\end{array}$} & \multicolumn{3}{|c|}{ Methylated } \\
\hline & & & Total & Type II & Type III \\
\hline C. nankingense & 584 & $274(46.9 \%)$ & $310(53.1 \%)$ & $178(30.5 \%)$ & $132(22.6 \%)$ \\
\hline T. vulgare & 572 & $275(48.1 \%)$ & 297 (51.9\%) & $164(28.7 \%)$ & $133(23.3 \%)$ \\
\hline Mid-parental value & $100 \%$ & $47.5 \%$ & $52.5 \%$ & $29.6 \%$ & $22.9 \%$ \\
\hline Hybrid & 567 & $292(51.5 \%)$ & $275(48.5 \%)$ & $148(26.1 \%)$ & $127(22.4 \%)$ \\
\hline C. crassum & 585 & $261(44.6 \%)$ & $324(55.4 \%)$ & $171(29.2 \%)$ & $153(26.2 \%)$ \\
\hline Cr. chinense & 572 & $268(46.9 \%)$ & $304(53.1 \%)$ & $162(28.3 \%)$ & $142(24.8 \%)$ \\
\hline Mid-parental value & $100 \%$ & $45.7 \%$ & $54.3 \%$ & $28.8 \%$ & $25.5 \%$ \\
\hline Hybrid & 573 & $284(49.6 \%)$ & 289 (50.4\%) & 149 (26.0\%) & $140(24.4 \%)$ \\
\hline
\end{tabular}

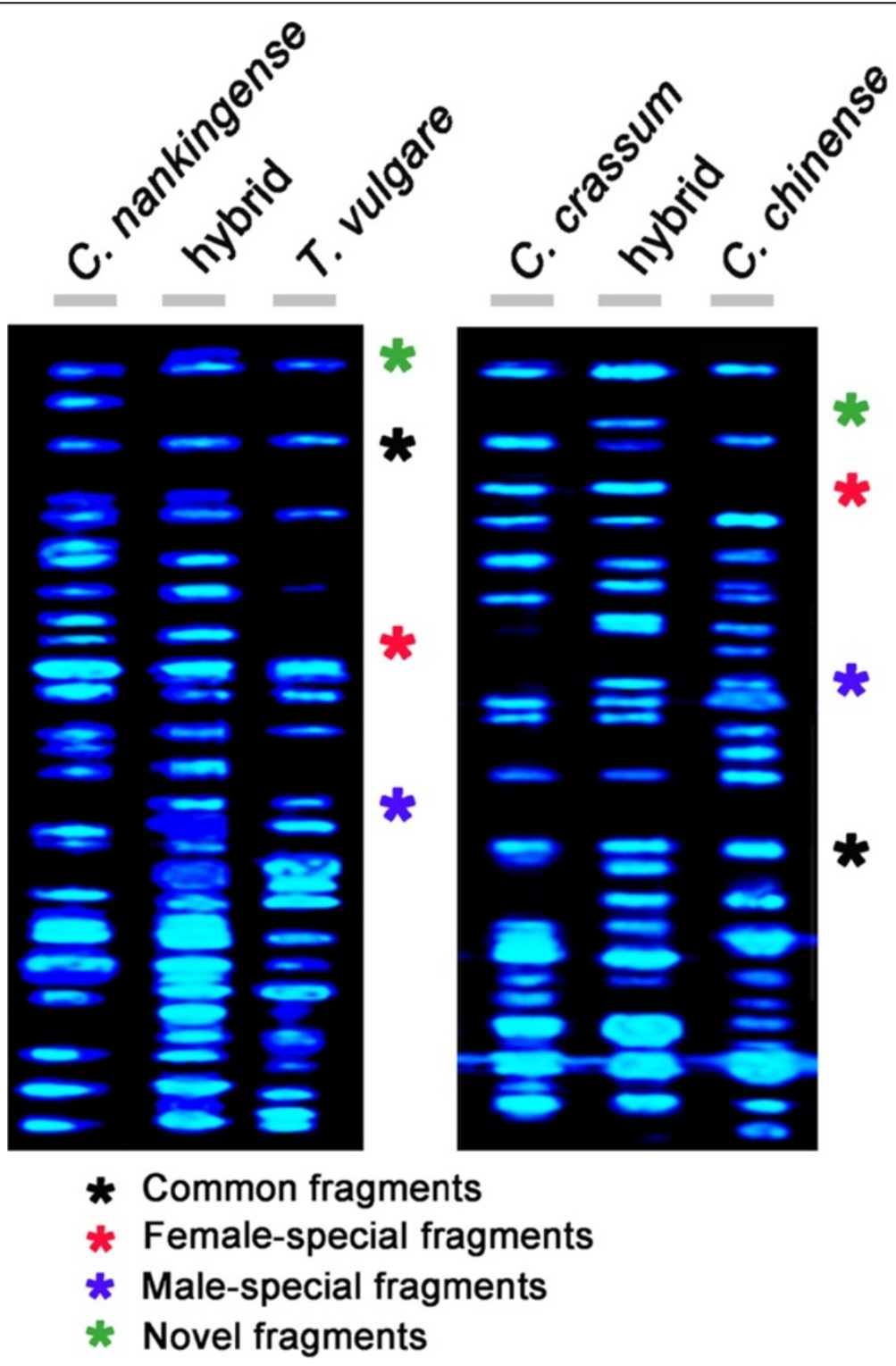

Figure 4 The various types of fragment generated by MSAP. Type I fragments are non-methylated, and appeared in both the H and M lanes, type II are fully-methylated, and were only detected in the M lanes, while type III are hemi-methylated, and were only detected in the $\mathrm{H}$ lanes. 
Table 5 Fragments type in two independent cDNA-AFLP analyses

\begin{tabular}{|c|c|c|c|c|}
\hline \multirow[t]{2}{*}{ Fragments type } & \multicolumn{2}{|c|}{$\begin{array}{c}\text { C. } \begin{array}{c}\text { nankingense } \\
\text { vulgare }\end{array} \\
\text {. }\end{array}$} & \multicolumn{2}{|c|}{$\begin{array}{l}\text { C. crassum } \times C r . \\
\text { chinense }\end{array}$} \\
\hline & Number & Percentage & Number & Percentage \\
\hline Common fragments & 155 & $50.5 \%$ & 166 & $52.2 \%$ \\
\hline $\begin{array}{l}\text { Female-special } \\
\text { fragments }\end{array}$ & 91 & $29.6 \%$ & 91 & $28.6 \%$ \\
\hline $\begin{array}{l}\text { Male-special } \\
\text { fragments }\end{array}$ & 52 & $16.9 \%$ & 46 & $14.5 \%$ \\
\hline Novel fragments & 9 & $3.0 \%$ & 15 & $4.7 \%$ \\
\hline Total fragments & 307 & $100 \%$ & 318 & $100 \%$ \\
\hline
\end{tabular}

A variety of analytical platforms has been exploited to show that de novo synthesized hybrids undergo massive genetic (chromosomal rearrangements, DNA sequence elimination) and epigenetic adjustment $[3,17,46]$. Rearrangements and deletions both have the potential to generate non-parental AFLP fragments in the hybrid's genomic DNA, if rearrangements and deletions affect restriction sites targeted by the procedure. Current consensus view is that the process of polyploidization is accompanied by the elimination of both low copy and/ or non-coding DNA sequence [18,47-50]. In synthetic wheat hybrids, deletion events have been proposed to be a major driver of the observed genomic changes [18], and an essentially similar conclusion was arrived at in Cucumis [51], Brassica [52] and Tragopogon [19]. Extensive loss of parental AFLP fragments from the hybrid's genome was a feature of both the $C$. nankingense $\times T$. vulgare and the C. crassum $\times C r$. chinense combinations. The deletion events were likely to have occurred very early in the process of hybrid zygote formation.

\section{Alterations in the epigenome of the newly synthesized allopolyploids}

Variation in the epigenome was explored via the MSAP technique, as illustrated in Figure 3. Type I (non-methylated) fragments were shared by the $\mathrm{H}$ and $\mathrm{M}$ lanes, type II (fully methylated) were only detected in M lanes, while type III (hemi-methylated) appeared only in the $\mathrm{H}$ lanes. The nine primer combinations employed generated 274 type I, 178 type II and 132 type III fragments in C. nankingense, and respectively 275, 164 and 133 in T. vulgare; the equivalent numbers of fragments in C. crassum were 261, 171 and 153, and in Cr. chinense 268, 162 and 142 (Table 4). Surprisingly, the global DNA methylation concentration in the diploids (51.9-53.1\%) was not much lower than that in the decaploid (55.4\%), as the expectation is that higher concentrations of ploidy are generally associated with more extensive DNA methylation.

Meanwhile, polymorphic fragments were also scored as methylation changes between hybrids and parents. The amount of cytosine methylation in the hybrids were $48.5 \%$ for $C$. nankingense $(53.1 \%) \times T$. vulgare $(51.9 \%$; $\left.U=1.36, U_{0.05}=1.96\right)$ and $50.4 \%$ for $C$. crassum $(55.4 \%) \times$ Cr. chinense (53.1\%; $U=1.31, U_{0.05}=1.96$; Table 4). With respect to fully methylated sites, the hybrids displayed lower $U$ values than predicted on the basis of mid-parent value (C. nankingense $\times$ T. vulgare: $U=1.31, C$. crassum $\times$ Cr. chinense: $U=1.06)$. With respect to the hemimethylated sites, the respective $U$ values were only 0.21 and 0.47 .

Present results suggested that the adjustments of DNA methylation patterns occurred widely at various genomic sites in each of the hybrid plants (Table 4). Combining two divergent genomes of distinct parental species in a new plant must generate the strong "shock", may disrupt intrinsic regulatory and developmental harmonies, possibly cause a myriad of incompatibilities at many layers, which is particularly important in plant evolution $[3,14,27,53]$. The occurrence and extent of methylation variation are dependent on genetic context of the hybrid. Nonetheless, the relative total frequencies of variation between the hybrids for a given combination are remarkably similar according to the present results. Thus, the similarity between the MSAP profiles of independent hybrids shows that epigenetic events do not occur stochastically, but rather are pre-determined in some way and might be a rapid process that occurred as early as in the $\mathrm{F}_{1}$ hybrid.

\section{Induced differences in the transcriptome}

Both hybrids grow larger and faster than the best of their parents (Figure 1D, F) [36,37]. cDNA-AFLP

Table 6 cDNA-AFLP fragments loss type in $F_{1}$ hybrids and their corresponding parents

\begin{tabular}{|c|c|c|c|c|c|c|c|c|}
\hline \multirow[t]{3}{*}{ Fragments type } & \multicolumn{4}{|c|}{ C. nankingense $\times T$. vulgare } & \multicolumn{4}{|c|}{ C. crassum $\times$ Cr. chinense } \\
\hline & \multirow[t]{2}{*}{ Number } & \multicolumn{3}{|c|}{ Total number } & \multirow[t]{2}{*}{ Number } & \multicolumn{3}{|c|}{ Total number } \\
\hline & & Female & Hybrid & Male & & Female & Hybrid & Male \\
\hline Female fragments loss & 8 & 259 & - & - & 9 & 271 & - & - \\
\hline Male fragments loss & 22 & - & - & 234 & 19 & - & - & 236 \\
\hline Common loss & 5 & - & - & - & 7 & - & - & - \\
\hline Novel fragments & 9 & - & 307 & - & 15 & - & 318 & - \\
\hline
\end{tabular}


profiling defined sets of transcript fragments which were either: (a) common to both parents and the hybrid (50.5\% of all the fragments in the C. nankingense $\times T$. vulgare cross and $52.2 \%$ in the other cross; (b) fragments which were specific to the female parent and which were inherited by the hybrid (29.6\% and $28.6 \%)$; (c) fragments which were specific to the male parent and which were inherited by the hybrid (16.9\% and 14.5\%), and (d) fragments in the hybrid which were not present in either parent (3.0\% and 4.7\%; Figure 4, Table 5). Meanwhile, there are 8 of $C$. nankingense, 22 of T. vulgare and 9 of C. crassum, 19 of $\mathrm{Cr}$. chinense cDNA fragments missed in cDNA-AFLP detection (Table 6), indicated that transcriptome divergence is reconciled during intergeneric hybridization but weaker than DNA sequences adjustment. Fragments of this sort may reflect the outcome of DNA sequence elimination and genome reorganization, although the possibility of organellar origin gene (in particular those sited in the chloroplast) expression or regulation cannot be excluded, since these cDNA is only transmitted to the hybrid via the female gamete.

Transcriptomic studies of hybridization in plants have revealed that patterns of gene transcripts likely have a profound effect in a hybrid context [15]. In spite of intensive study for approximately a century, the molecular basis of heterosis remains unclear. Genome-wide transcriptomic alterations correlates with the expression divergence between the parents have been observed in the hybrid [13,26,54]. Expression profiles in hybrids formed from very wide crosses have repeatedly been revealed to be non-additive, which provides a possible molecular lead in explaining heterosis [27] and phenotypic variation in the hybrid progeny [24]. An admitted suggestion holds that epigenetic mechanisms are important for regulating the relative abundance of gene transcripts $[25,55]$. Genomic shock can disrupt a number of regulatory and developmental processes, particularly via changes to the epigenome given that hypermethylation is associated with gene silencing, whereas hypomethylation is often associated with gene activity [56]. The MSAP analysis suggested that DNA methylation was at a lower degree in the hybrids than in their corresponding parents, a finding which could explain the origin of at least some of the non-parental cDNA-AFLP fragments present in the hybrids [57,58]. Elucidating the ways in which altered DNA methylation patterns, either at the whole genomic level or at specific sites can affect genome stability during a hybridization event will require substantial additional investigation [59].

\section{Conclusion}

In conclusion, large scale genomic, epigenomic and transcriptomic changes accompanied the process of hybridization in the crosses $C$. nankingense $\times T$. vulgare and C. crassum $\times$ Cr. chinense. The forced union of two distinct genomes induced many changes to both the genome and the transcriptome. The former changes were largely brought about by the elimination of DNA, while the latter reflected in addition the effect of altered amount of cytosine methylation. Together, these rapid changes could drive the evolutionary process of the freshly formed intergeneric hybrids.

\section{Competing interests}

The authors have no competing interests to declare.

\section{Authors' contributions}

Conceived and designed the experiments: HW FC JJ SC. Performed the experiments: HW FC JJ. Analyzed the data: HW JW. Contributed reagents/ materials/analysis tools: WF ZG. Wrote the paper: HW JJ SC. All authors read and approved the final manuscript

\section{Acknowledgments}

This research was supported by the National Natural Science Foundation of China (Grant No. 31071820, 31071825, 31272203, 31272196), 863 project (2011AA100208).the Fundamental Research Funds for the Central Universities (KYZ201112, KYZ201147), the Program for New Century Excellent Talents in University of Chinese Ministry of Education (Grant No. NCET-10-0492, NCET-12-0890), and Youth Science and Technology Innovation Fund (KJ2011009), and A Project Funded by the Priority Academic Program Development of Jiangsu Higher Education Institutions.

Received: 14 June 2013 Accepted: 13 December 2013

Published: 18 December 2013

\section{References}

1. Paun O, Fay MF, Soltis DE, Chase MW: Genetic and epigenetic alterations after hybridization and genome doubling. Taxon 2007, 56(3):649-656.

2. Kearney M: Hybridization, glaciation and geographical parthenogenesis. Trends ecol evol 2005, 20(9):495-502.

3. Chen ZJ: Genomic and epigenetic insights into the molecular bases of heterosis. Nat Rev Genet 2013, 14:471-482

4. Jiao Y, Wickett NJ, Ayyampalayam S, Chanderbali AS, Landherr L, Ralph PE, Tomsho LP, Hu Y, Liang H, Soltis PS, et al: Ancestral polyploidy in seed plants and angiosperms. Nature 2011, 473(7345):97-100.

5. Chen ZJ, Ni Z: Mechanisms of genomic rearrangements and gene expression changes in plant polyploids. Bioessays 2006, 28(3):240-252.

6. Soltis D, Soltis P, Rieseberg DLH: Molecular data and the dynamic nature of polyploidy. Criti Rev Plant Ssci 1993, 12(3):243-273.

7. Soltis DE, Soltis PS: Polyploidy: recurrent formation and genome evolution. Trends ecol evol 1999, 14(9):348-352.

8. Mandakova T, Joly S, Krzywinski M, Mummenhoff K, Lysak MA: Fast diploidization in close mesopolyploid relatives of Arabidopsis. The Plant cell 2010, 22(7):2277-2290.

9. Yu J, Wang J, Lin W, Li S, Li H, Zhou J, Ni P, Dong W, Hu S, Zeng C, et al: The genomes of Oryza sativa: a history of duplications. PLoS biology 2005, 3(2):e38.

10. Gaut BS: Patterns of chromosomal duplication in maize and their implications for comparative maps of the grasses. Genome research 2001, 11(1):55-66.

11. Hegarty MJ, Hiscock SJ: Genomic clues to the evolutionary success of polyploid plants. Current bio/ CB 2008, 18(10):R435-444.

12. Rieseberg LH, Raymond O, Rosenthal DM, Lai Z, Livingstone K, Nakazato T, Durphy JL, Schwarzbach AE, Donovan LA, Lexer C: Major ecological transitions in wild sunflowers facilitated by hybridization. Science 2003, 301(5637):1211-1216.

13. Hochholdinger $F$, Hoecker $N$ : Towards the molecular basis of heterosis Trends plant sci 2007, 12(9):427-432.

14. McClintock B: The significance of responses of the genome to challenge. Physiology or Medicine Literature Peace Eeconomic Sciences 1983:180.

15. Hegarty MJ, Barker GL, Brennan AC, Edwards KJ, Abbott RJ, Hiscock SJ: Changes to gene expression associated with hybrid speciation in plants: 
further insights from transcriptomic studies in Senecio. Philos Trans Royal Soc B Biol Sci 2008, 363(1506):3055-3069.

16. Kawakami T, Dhakal P, Katterhenry AN, Heatherington CA, Ungerer MC: Transposable element proliferation and genome expansion are rare in contemporary sunflower hybrid populations despite widespread transcriptional activity of LTR retrotransposons. Genome biol evol 2011, 3:156-167.

17. Xiong Z, Gaeta RT, Pires JC: Homoeologous shuffling and chromosome compensation maintain genome balance in resynthesized allopolyploid Brassica napus. Proc Natl Acad Sci USA 2011, 108(19):7908-7913.

18. Shaked H, Kashkush K, Ozkan H, Feldman M, Levy AA: Sequence elimination and cytosine methylation are rapid and reproducible responses of the genome to wide hybridization and allopolyploidy in wheat. Plant cell 2001, 13(8):1749-1759.

19. Tate JA, Ni Z, Scheen AC, Koh J, Gillbert CA, Lefkowitz D, Chen ZJ, Soltis PS, Soltis DE: Evolution and expression of homeologous loci in Tragopogon miscellus (Asteraceae), a recent and reciprocally formed allopolyploid. Genetics 2006, 173(3):1599-1611.

20. Axelsson T, Bowman CM, Sharpe AG, Lydiate DJ, Lagercrantz U: Amphidiploid Brassica juncea contains conserved progenitor genomes. Genome National Res Counc Can 2000, 43(4):679-688.

21. Liu B, Brubaker CL, Mergeai G, Cronn RC, Wendel JF: Polyploid formation in cotton is not accompanied by rapid genomic changes. Genome National Res Counc Can Genome 2001, 44(3):321-330.

22. Baumel A, Ainouche M, Kalendar R, Schulman AH: Retrotransposons and genomic stability in populations of the young allopolyploid species Spartina anglica C.E. Hubbard (Poaceae). Mol biol evol 2002, 19(8):1218-1227.

23. Osborn TC, Pires JC, Birchler JA, Auger DL, Chen ZJ, Lee HS, Comai L, Madlung A, Doerge RW, Colot V, et al: Understanding mechanisms of novel gene expression in polyploids. Trends genet TIG 2003, 19(3):141-147

24. Chen ZJ: Genetic and epigenetic mechanisms for gene expression and phenotypic variation in plant polyploids. Annu Rev Plant Biol 2007, 58:377.

25. Zhao X, Chai Y, Liu B: Epigenetic inheritance and variation of DNA methylation level and pattern in maize intra-specific hybrids. Plant $\mathrm{SC}$ 2007, 172(5):930-938.

26. Lippman ZB, Zamir D: Heterosis: revisiting the magic. Trends genet $T / G$ 2007, 23(2):60-66.

27. Birchler JA, Auger DL, Riddle NC: In search of the molecular basis of heterosis. Plant cell 2003, 15(10):2236-2239.

28. Ellis J: Fragaria-Potentilla intergeneric hybridization and evolution in fragaria. In Proceedings of the Linnean Society of London. Wiley Online Library; 1962:99-106.

29. Ozkan H, Levy AA, Feldman M: Allopolyploidy-induced rapid genome evolution in the wheat (Aegilops-Triticum) group. Plant Cell 2001, 13(8):1735-1747.

30. Zhang SZ, Wang YL, He ZC, Ejder E: Genome differentiation in Magonoliaceae as revealed from meiotic pairing in interspecific and intergeneric hybrids. J Syst Evol 2011, 49(6):518-527.

31. Liu PL, Wan Q, Guo YP, Yang J, Rao GY: Phylogeny of the genus Chrysanthemum L.: Evidence from single-copy nuclear gene and chloroplast DNA sequences. PloS one 2012, 7(11):e48970.

32. Bremer K, Humphries CJ: Generic monograph of the AsteraceaeAnthemideae. Bull Nat Hist Mus Bot ser 1993, 23(2):71-177.

33. Hegarty MJ, Jones JM, Wilson ID, Barker GL, Coghill JA, Sanchez P, Liu G, Buggs RJ, Abbott RJ, Edwards KJ: Development of anonymous CDNA microarrays to study changes to the Senecio floral transcriptome during hybrid speciation. Mol ecol 2005, 14(8):2493-2510.

34. Guo YP, Wang SZ, Vogl C, Ehrendorfer F: Nuclear and plastid haplotypes suggest rapid diploid and polyploid speciation in the $\mathrm{N}$ Hemisphere Achillea millefolium complex (Asteraceae). BMC evol biol 2012, 12:2.

35. Malinska H, Tate JA, Matyasek R, Leitch AR, Soltis DE, Soltis PS, Kovarik A: Similar patterns of rDNA evolution in synthetic and recently formed natural populations of Tragopogon (Asteraceae) allotetraploids. BMC evol biol 2010, 10:291.

36. Tang $F$, Chen F, Chen $S$, Teng $N$, Fang W: Intergeneric hybridization and relationship of genera within the tribe Anthemideae Cass.(I. Dendranthema crassum (kitam.) kitam. $\times$ Crossostephium chinense (L.) Makino). Euphytica 2009, 169(1):133-140.
37. Tang F, Wang H, Chen S, Chen F, Liu Z, Fang W: Intergeneric hybridization between Dendranthema nankingense and Tanacetum vulgare. Sci Hortic 2011, 132:1-6.

38. Stewart CN Jr, Via LE: A rapid CTAB DNA isolation technique useful for RAPD fingerprinting and other PCR applications. Biotechniques 1993, 14(5):748-750.

39. Sambrook J, Russell DW: Molecular cloning: a laboratory manual. Volume 1-3. In Cold Spring Harbor. New York: Cold Spring Harbor Laboratory Press; 2001.

40. Vos $\mathrm{P}$, Hogers R, Bleeker M, Reijans M, van de Lee $T$, Hornes M, Friters A, Pot J, Paleman J, Kuiper M: AFLP: a new technique for DNA fingerprinting. Nucleic acids res 1995, 23:4407-4414

41. Roberts RJ, Vincze T, Posfai J, Macelis D: REBASE-enzymes and genes for DNA restriction and modification. Nucleic acids res 2007, 35:269-270.

42. Benhattar J, Clement G: Methylation-sensitive single-strand conformation analysis: a rapid method to screen for and analyze DNA methylation. Methods Mol Biol 2004, 287:181-193.

43. Guo M, Lightfoot D, Mok M, Mok D: Analyses of Phaseolus vulgaris L. and $P$. coccineus Lam. hybrids by RFLP: preferential transmission of $P$. vulgaris alleles. Theor Appl Genet 1991, 81(5):703-709.

44. Guo M, Lightfoot DA, Mok MC, Mok DW: RFLP analyses of phaseolus interspecific hybrids. Hortsci 1990, 25(9):1158-1158.

45. Paun O, Stuessy TF, Horandl E: The role of hybridization, polyploidization and glaciation in the origin and evolution of the apomictic Ranunculus cassubicus complex. New phytol 2006, 171(1):223-236.

46. Barton NH: The role of hybridization in evolution. Mol ecol 2001، 10(3):551-568.

47. Soltis DE, Soltis $P S$, Bennett MD, Leitch IJ: Evolution of genome size in the angiosperms. Am j bot 2003, 90(11):1596-1603.

48. Feldman M, Liu B, Segal G, Abbo S, Levy AA, Vega JM: Rapid elimination of low-copy DNA sequences in polyploid wheat: a possible mechanism for differentiation of homoeologous chromosomes. Genetics 1997, 147(3):1381-1387.

49. Dadejova M, Lim KY, Souckova-Skalicka K, Matyasek R, Grandbastien MA, Leitch A, Kovarik A: Transcription activity of rRNA genes correlates with a tendency towards intergenomic homogenization in Nicotiana allotetraploids. New phytol 2007, 174(3):658-668

50. Pellicer J, Garcia S, Canela MA, Garnatje T, Korobkov AA, Twibell JD, Valles J: Genome size dynamics in Artemisia L. (Asteraceae): following the track of polyploidy. Plant Biol (Stuttg) 2010, 12(5):820-830.

51. Chen L, Lou Q, Zhuang Y, Chen J, Zhang X, Wolukau JN: Cytological diploidization and rapid genome changes of the newly synthesized allotetraploids Cucumis x hytivus. Planta 2007, 225(3):603-614.

52. Song K, Lu P, Tang K, Osborn TC: Rapid genome change in synthetic polyploids of Brassica and its implications for polyploid evolution. Proc Natl Acad Sci USA 1995, 92(17):7719-7723.

53. Adams KL, Wendel JF: Polyploidy and genome evolution in plants. Curr opin plant biol 2005, 8(2):135-141.

54. Meyer RC, Torjek O, Becher M, Altmann T: Heterosis of biomass production in Arabidopsis. Establishment during early development. Plant physiol 2004, 134(4):1813-1823.

55. Sun Q, Wu L, Ni Z, Meng F, Wang Z, Lin Z: Differential gene expression patterns in leaves between hybrids and their parental inbreds are correlated with heterosis in a wheat diallel cross. Plant Sci 2004, 166(3):651-657.

56. Martienssen RA, Colot V: DNA methylation and epigenetic inheritance in plants and filamentous fungi. Science 2001, 293(5532):1070-1074.

57. Finnegan EJ: Epialleles - a source of random variation in times of stress. Curr opin plant biol 2002, 5(2):101-106.

58. Finnegan EJ: Is plant gene expression regulated globally? Trends in genet TIG 2001, 17(7):361-365.

59. Koh J, Soltis PS, Soltis DE: Homeolog loss and expression changes in natural populations of the recently and repeatedly formed allotetraploid Tragopogon mirus (Asteraceae). BMC genomics 2010, 11:97.

doi:10.1186/1471-2164-14-902

Cite this article as: Wang et al:: Rapid genomic and transcriptomic alterations induced by wide hybridization: Chrysanthemum nankingense $\times$ Tanacetum vulgare and C. crassum $\times$ Crossostephium chinense (Asteraceae). BMC Genomics 2013 14:902 